\title{
Present Status of Computational Tools for Maglev Development
}

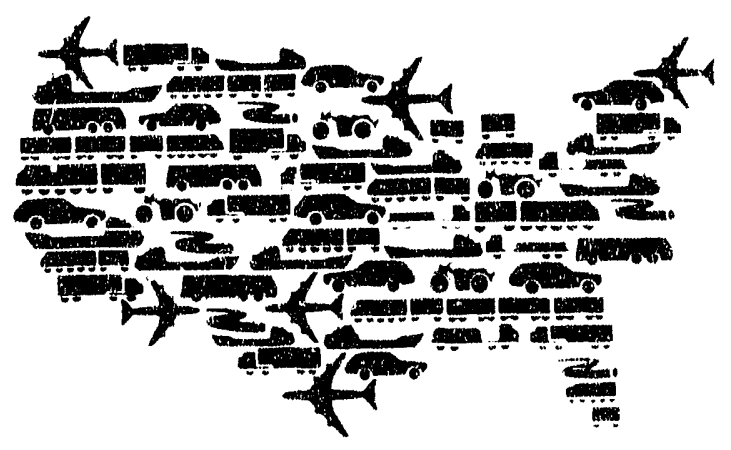

Center for Transportation Research Argonne National Laboratory 


\section{Argonne National Laboratory}

Argonne National Laboratory, with facilities in the states of Illinois and Idaho, is owned by the United States govemment, and operated by the University

of Chicago under the provisions of a contract with the Department of Energy,

This technical memo is a pruduct of Argonne's Energy Systems (ES)

Division. For infonnation on the division's scientific and engineering

activities, contact:

Director, Energy Systems Division

Argonne National Laboratory

Argonne, Illinois $60439-4815$

Telephone (708) 252-3724

Presented in this technical memo are preliminary results of ongoing work or work that is more limited in scope and depth than that described in formal reports issued by the ES Division.

\section{Disclaimer}

This report was prepared as an account of work sponsored by an agency of the United States Govemment. Neither the United States Govemment nor any agency thereof, nor any of their employees, makes any warranty, express or implied, or assumes any legal liability or responsibility for tho accuracy, completeness, or usefulness of any information, apparatus, product, or process clisclosed, or represents that its use would not infringe privately owned rights. Reference herein to any specific commercial product, process, or service by trade name, trademark, manufacturer, or otherwise, does not necessarily constitute or imply its endorsement, recommendation, or favoring by the United States Govemment or any agency thereot. The views arid opinions of authors expressed herein do not necessarily state or reflect those of the United States Government or any agency thereof.

Roproduced directly from the best available copy.

Available to DOE and DOE contractors from the Office of Scientific and Technical Information, P.O. Box 62, Oak Ridge, TN 37831; prices available from (615) 576-8401, FTS 626-8401.

Available to the public from the National Tochnical Information Service, U.S. Departmont of Commerco, 5285 Port Royal Road, Springfield, VA 22161. 


\section{Present Status of Computational Tools for Maglev Development}

by Z. Wang, S.S. Chen, and D.M. Rote

Center for Transportation Research, Energy Systerns Division,

Argonne National Laboratory, 9700 South Cass Avenue, Argonne, Illinois 60439

Octoher 1991

Work sponsored by United States Army Corps of Engineers 


\section{Contents}

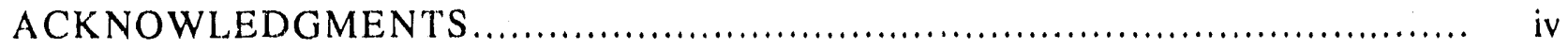

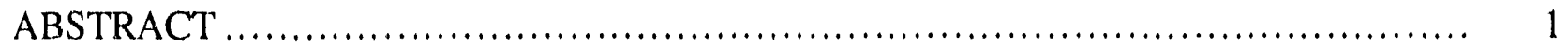

1 INTRODUCTION ............................................................

2 PROBLEMS ASSOCIATED WITH MAGLEV RESEARCH ......................... 6

2.1 Computational Tools for Electromagnetic Forces and Fields ..................... 6

2.1 .1 Propulsion Systems ................................................. 6

2.1.2 Suspension-System Design ......................................... 7

2.1 .3 Force Computation .................................................. 8

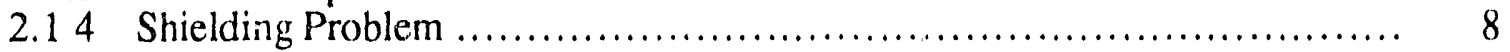

2.1.5 Edge-Effect Problem.................................................... 9

2.1.6 End-Effect Problem................................................. 10

2.1.7 Existing Software Packages ................................... 10

2.2 Computational Tools for Mechanical Forces and Dynamics........................ 24

2.2 .1 Vehicle Model ................................................... 24

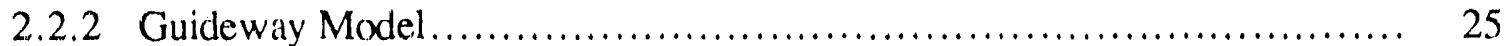

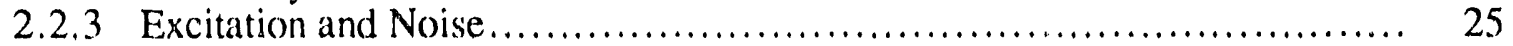

2.2 .4 Vehicle/Guideway Interaction ...................................... 27

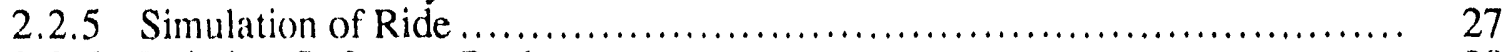

2.2 .6 Existing Software Packages .................................... 28

3 CONCLUSIONS AND RECOMMENDATIONS .................................. 42

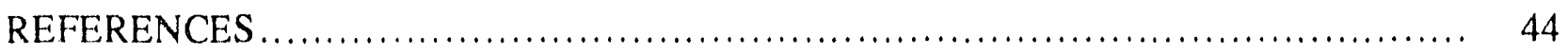

APPENDIX A: Questionnaire and Letter Used in Survey of Computer Codes ............. 47

APPENDIX B: Introduction to Dynamic Circuit Theory....................................... 49

\section{Figures}

1 Electromagnetic Aspects of Maglev Research Topics ................................. 4

2 Mechanical Aspects of Maglev Research Topics..................................... 5

\section{Tables}

1 Capabilities of Two-Dimensional Software Packages................................ 11

2 Capabilities of Three-Dimensional Soltware Packages........................................ 12 


\section{Acknowledgments}

The authors wish to acknowledge the following persons and their respective companies for responding to the survey:

\section{Name}

R. Rohonczy

D.B. Cherchas

R. Clanton

L.C. Davis

T.R. Eastham

A.R. George

C. Henning

R.J. Hill

L. Marzolf and T. Horanic

M.M. Jenich

L. Kettunen

P.Z. Klauser

H.H. Kolm

S. Kuznetsov

G. List

S. Pissanetzky

C.J. Russo

D. Rudger

S.J. Salon

H.C. Schrader

J.A. Sherry

T.L. Shiels

R.J. Lari

J. Smith

K.F. Szymanski

W. Toscano

E. Travers

L. Vu-Quoc

P.F. Wendling

C.K. Wood

\section{Organization}

Infolytica Corporation

University of British Columbia

Westinghouse Electric Corporation

Ford Motor Company

Queen's University

Cornell University

Lawrence Livermore National Laboratory

University of Bath

KIT Corporation

The MacNeal-Schwendler Corporation

Argonne National Laboratory

Assceiation of American Railroads

Magneplane International, Inc.

PSM Technologies, Inc.

Railway Engineering Associates, Inc.

MAGNUS Software Corporation

American Superconductor Corporation

University of Bath

Rensselaer Polytechnic Institute

USR Consultants

Integrated Engineering Software, Inc.

MARC Analysis Research Corporation

Vector Fields, Inc.

Quantic Laboratories, Inc.

Ansoft Corporation

Mitchell and Gauthier Associates, Inc.

Swanson Analysis Systems, Inc

University of Florida

Magsoft Corporation

Physitron, Inc.

Sabbagh Associates, Inc.

The authors would also like to acknowledge R. Armstrong and B. Zehrt, U.S. Army Corps of Engineers, Huntsville, Ala., for reviewing the manuscript; K. Brown, Argonne National Laboratory (ANL), for technical editing; L. Crosser, ANL, for word processing; and L. Culbert, ANL, for graphics. 


\title{
Present Status of Computational Tools for Maglev Development
}

\author{
by \\ Z. Wang, S.S. Chen, and D.M. Rote
}

\begin{abstract}
High-speed vehicles that employ magnetic levitation (maglev) have received great attention worldwide as a means of relieving both highway and air-traffic congestion. At this time, Japan and Germany are leading the development of maglev. After fifteen years of inactivity that is attributed to technical policy decisions, the federal government of the United States has reconsidered the possibility of using maglev in the United States. The National Maglev Initiative (NMI) was established in May 1990 to assess the potential of maglev in the United States. One of the tasks of the NMI, which is also the objective of this report, is to determine the status of existing computer software that can be applied to maglevrelated problems. The computational problems involved in maglev assessment, research, and development can be classified into two categories: electromagnetic and mechanical. Because most maglev problems are complicated and difficult to solve analytically, proper numerical methods are needed to find solutions. To determine the status of maglev-related software, developers and users of computer codes were surveyed. The results of the survey are described in this report.
\end{abstract}

\section{Introduction}

Worldwide, over the past twenty years, many researchers and engineers have been interested in studying, designing, and developing high-speed vehicles that employ magnetic levitation (maglev) as a means of relieving both highway and air-traffic congestion. Several fullscale prototype models that can carry passengers at speeds of $250 \mathrm{mph}$ have been developed in Japan (Fujie 1989; JNR 1983) and Germany (Menden, Mayer, and Rogg 1989; Miller and Rouss 1989). The United States was very active in maglev research in the late 1960s and early 1970s (Coffey, Chilton, and Hoppie 1971; Coffey, Chilton, and Barbee 1969). Unfortunately, federal support was withdrawn in 1975, and most maglev projects were shut down. Little progress has been reported in the United States since that time.

During recent years, however, the federal government has begun to take a second look at the possibility of using maglev in the United States. The National Maglev Initiative (NMI) was established in May 1990. The NMI is organized by three government agencies: the Federal Railroad Administration, the U.S. Army Corps of Engineers, and the U.S. Department of Energy (DOE). The major near-term goal of the NMI is to determine which of the following three options should be selected for the development and implementation of maglev in the United States: 
(1) provide assistance in implementing an existing foreign technology, (2) form a cooperative development program based on an existing foreign technology, or (3) develop a next-generation technology in the United States. The NMI is currently assessing various technical and economic issues involving maglev technology and evaluating the potential impacts of maglev on the environment, human health and safety, and energy consumption. The status of computational tools for maglev development is one of the more important concerns to the NMI.

The objective of this document is to report the findings of a survey of computer code users and developers that was conducted to ascertain the status of such codes. However, before proceeding with the report, one needs to understand the basic theory of maglev and the existing problems in maglev research that require the use of computational tools.

Fundamentally, maglev vehicles differ from conventional vehicles in that they lack mechanical contact with the guideway; the vehicle is supported, guided, and propelled by magnetic forces. Two principal types of maglev systems have been extensively developed: the repulsiveforce or electrodynamic suspension (EDS) system and the attractive-force or electromagnetic suspension (EMS) system. The Japanese maglev model is based on the EDS system, while the German model is based on the EMS system. In an EDS system, superconducting magnets are carried aboard the vehicle to achieve a high levitation height. Eddy currents are induced in shorted conducting coils on the guideway when vehicle-borne superconducting magnets pass over them. Repulsive magnetic forces are produced by the interaction between the eddy currents and the magnetic fields. The main advantages of the EDS system are inherent stability, high payload efficiency, and large clearance. Possible shortcomings of the EDS system include the problem of shielding the passenger compartment of the vehicle from the magnetic field and the need for mechanical support at rest and at speeds below the lift-off value of about $20 \mathrm{~m} / \mathrm{s}$.

In an EMS system, conventional electromagnets are fixed to the vehicle and are attracted upward toward ferromagnetic rails attached to the underside of the guideway above the magnets. Altractive magnetic forces are produced by the interaction between the electromagnets and the ferromagnetic rails. The main advantages of the EMS system are high overall operation efficiency and a low magnetic field around the vehicle. The major disadvantages of the EMS system are inherent instability, small clearance (which requires very close tolerances on the guidewaymounted components), and high vehicle weight (attributable to iron-core magnets and on-board power condiitoning and control equipment).

Several methods have been proposed for propelling maglev vehicles, including long-stator linear synchronous motors, long-stator linear induction motors, short-stator linear synchronous motors, and short-stator linear induction motors. Theoretically, any one of these motrers can be combined with EMS or EDS to form a maglev system. However, for practical reasons (Johnson et al. 1989), the most compatible means of propulsion is the long-stator linear synchronous motor.

Essentially, the basic elements of a maglev-vehicle system consist of the vehicle; guideway structural support; guideway electrical conductors used for propulsion, levitation (or suspension), and guidance; a power distribution system; redundant braking systems; guideway sensors; and an operational control system. Associated with each element are electromagnetic and mechanical research problems, the solutions of which require the proper computational tools. Figures 1 and 2 
summarize a number of electromagnetic and nechanical dynamic problems, respectively. To solve these problems, physical, mathematical, and computer models must be generated. Most of the problems require the treatment (i.e., formulation of models) of one or more of the following physical factors:

1. Magnetic field distributions for given coil geometries and excitations, as well as for relative motion.

2. Levitation, guidance, drag, and propulsion forces, as well as eddy current and magnetic field distributions for various coil geometries, excitations, and relative motions.

3. Dynamic response of vehicles and guideway structures.

4. Estimates of ride quality.

5. Aerodynamic drag and lateral forces, as well as noise emissions from vehicle/guideway configurations.

6. Propulsion and power system design and operating parameters.

After a physical model is established that incorporates the main physical factors, a corresponding mathematical model can be generated. The mathematical model could apply to one, two, or three dimensions of space, depending upon the geometry of the problem and the required accuracy of the results. In order to solve mathematical equations, appropriate methods (either analytical or numerical) must be found. Because it is usually difficult to obtain analytical solutions for most of the problems, numerical solutions are generally required. Several numerical methods are available, such as the finite element method, the boundary element method, the finite difference method, Fourier transformation and harmonic analysis, and the dynamic circuit theory method. The objective of this report is to survey the existing computer software and to evaluate how effectively the codes can be applied to maglev-related problems, as well as the extent to which they have been verified, validated, and documented for use.

The remainder of the report is made up of two sections. Section 2 discusses the problems associated with maglev research and describes the tools for solving electromagnetic and mechanical problems. Section 3 provides conclusions and makes recommendations on the basis of the information provided in Section 2. 


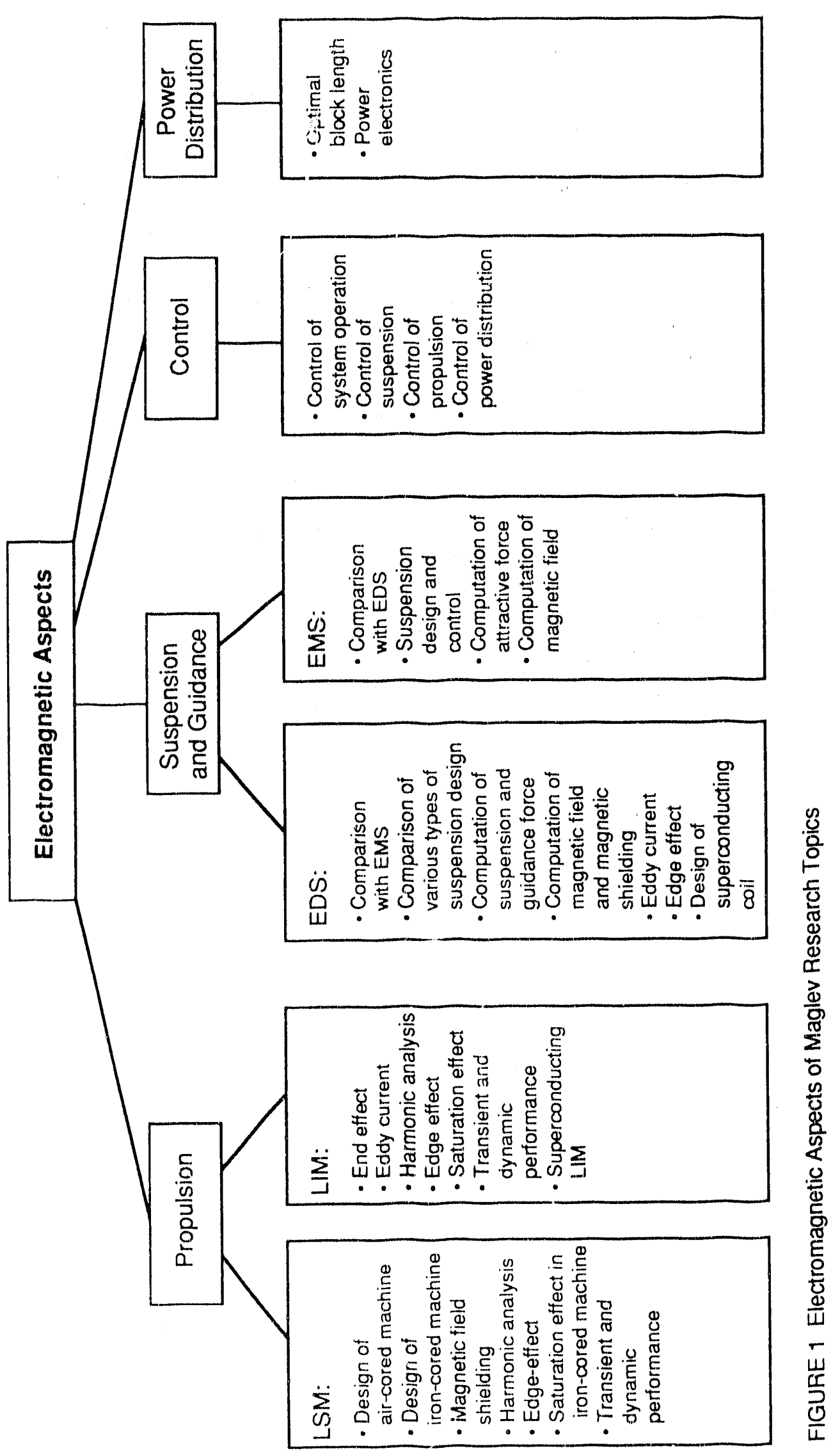




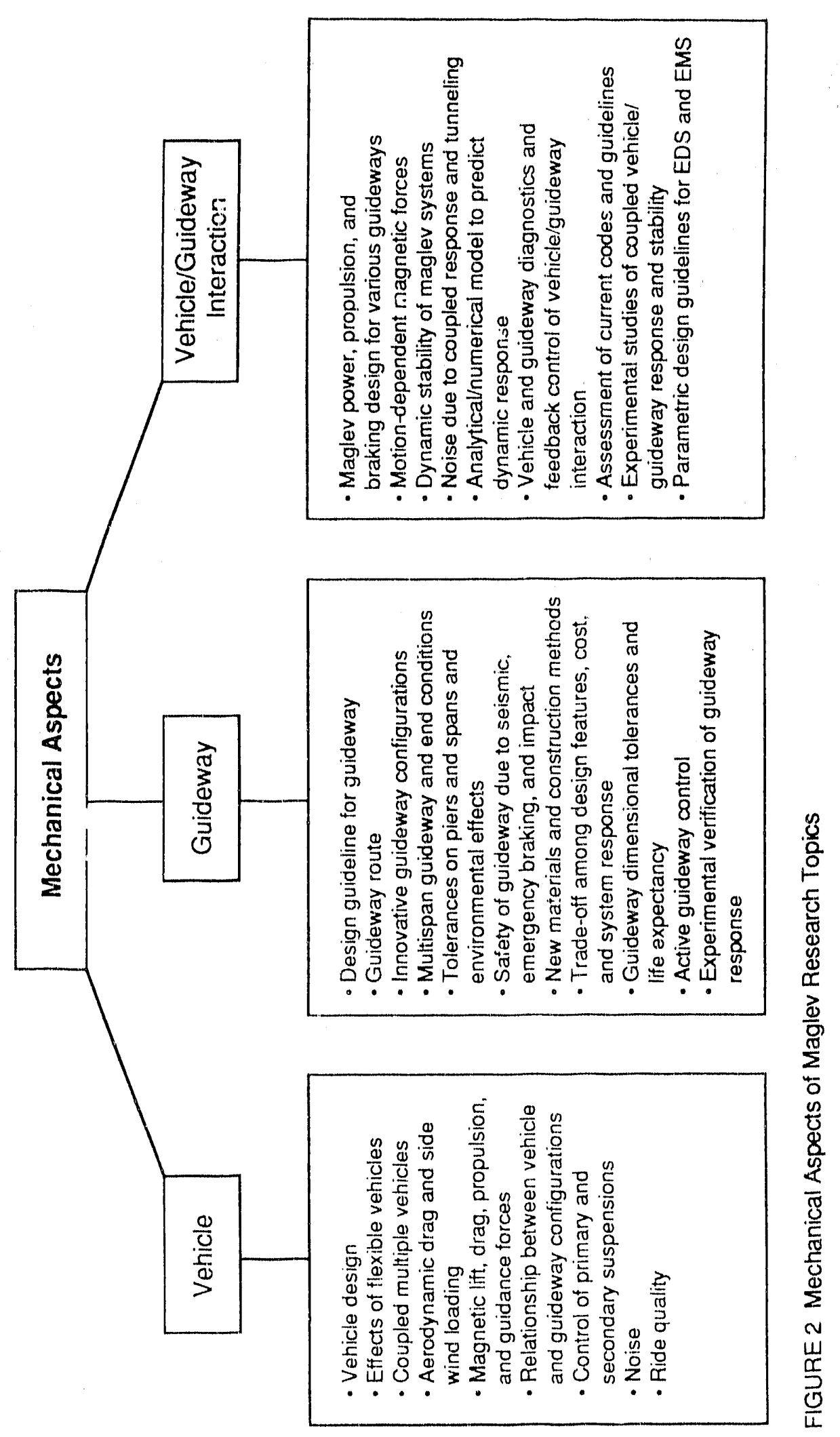




\section{Problems Associated with Maglev Research}

\subsection{Computational Tools for Electromagnetic Forces and Fields}

Research on maglev technology involves the solution of various technical problems associated with electromagnetic fields. Some of these problems are considered in this section.

\subsubsection{Propulsion Systems}

Two major types of linear machines are used in maglev systems to produce propulsive forces: linear synchronous machines (LSM) and linear induction machines (LIM). The EDS maglev system ases air-cored long-stator LSM, the propulsive force for which is generated by the interaction between the superconducting magnets aboard the vehicle and the magnetic traveling wave produced by polyphase stator windings mounted on the gadeway. The Japanese maglev prototype at Miyazahi uses air-cored LSM for propulsion. The EMS maglev system (e.g., the German Transrapid) employs iron-cored long-stator LSM in which magnets excited with controlled direct-current (DC) power are used aboard the vehicle, and the three-phase windings on the guideway are enclosed by ferromagnetic lamination cores. The iron-cored LSMs are similar to conventional synchronous motors, and most of the conventional machinery theory can be directly applied to EMS systems. Two major problems are associated with the air-cored LSM used for maglev applications that are closely related to this survey:

1. The generation of spatial harmonics caused by the discontinuous distribution of superconducting magnets.

2. The generation of magnetic fields caused by the strong field magnets needed for high motor performance. The passenger compartments of maglev vehicles need to be shielded from these fields.

Similarly, there are problems associated with the use of LIM to produce propulsive forces. There are two types LIM: the short-stator LIM and the long-stator LIM. For a short-stator LIM, current pick-up at high speed is a serious problem, because the vehicle will be powered by power supplies off the vehicle. For a long-stator LIM, the scheme is similar to the long-stator LSM, except that a passive reaction plate, rather than controlled DC excitation coils, is mounted on the vehicle. The major problems of a long-stator LIM are that (1) very large currents need to flow through the three-phase windings in order to produce the desired propulsion forces and (2) the power factor is very poor because most of the power is reactive rather than real. One potentially fruitful research topic is to investigate the feasibility of designing a superconducting LIM, thereby improving the perfurmance of LIM and avoiding the need to use superconductor winding along the length of the guideway. In this case, a short-stator LIM would have to be used. 


\subsubsection{Suspension-System Design}

The suspension system is one of the main parts of the guideway. As mentioned earlier, EMS and EDS are two major types of suspensions. In the EMS systen, the attractive force is produced by the interaction between conventional iron-core, copper-wire-wound electromagnets on the vehicle and ferromagnetic rails on the guideway. The EDS system uses repulsive forces between superconducting air-core magnets on the vehicle and eddy current induced in continuous conductive sheets or discrete coils mounted on the guideway. In addition, another suspension system based on repulsive forces exists, the alternating-current (AC) induction system. An example of this type of system is the "magnetic river" (Laithwaite 1987). Among the three types of suspension systems, many investigators favor EDS. To date, most of the research and development effort on EDS systems has focused on the use of three distinctly different guideway conductor designs:

1. Continuous-sheet suspension:

The operating principle of a continuous-sheet guideway is as follows: superconducting coils aboard the vehicle are energized by large persistent currents that induce corresponding large eddy currents in the conducting sheets; these two currents interact each other to produce the repulsive levitation force. The net repulsive force is roughly the product of these two currents.

2. Loop-shaped coil suspension:

In a loop-shaped or shorted-turn coil suspension system, superconducting coils are levitated above the loop-shaped coil guideway instead of above a continuous sheet guideway. A loop-shaped coil guideway is considered superior to a continuous sheet guideway because a loop-shaped coil guideway will produce lower magnetic drag forces. Generally, because the induced eddy currents are smaller, the excitation currents must be larger in order to produce the same net product (i.e., repulsive force).

3. Figure-eight-shaped null-flux coil suspension:

The concept of a figure-eight-shaped null-flux coil suspension was invented by J. Powell and G. Danby in the late 1960s (see Powell and Danby 1969). The major merit of figure-cight-shaped coils is that both suspension and guidance forces can be produced with a relatively low drag force. When compared with loop-shaped coils of the same dimensions, however, the suspension force produced by figure-eight-shaped coils is also low.

Other types of guideways may be superior to the three mentioned above. To study and compare various EDS conductor configurations, three-dimensional computer models that incorporate a treatment of moving conductors have to be used. In some cases, for example, when edge effects or end effects can be ignored to a first approximation, two-dimensional computer 
models may be quite useful. Examples include the continuous sheet guideway conductor-EDS system, EMS systems involving continuous iron rails, and $\mathrm{AC}$ induction systems.

\subsubsection{Force Computation}

Force computation is one of the most important aspects of maglev research. The following electromagnetic forces are necessary: levitation, propulsion (and drag), and guidance. These forces act on each magnet that is mounted either rigidly or through a secondary suspension system to the vehicle body that is, itself, either rigid or flexible. If it is rigid, then there are six degrees of freedom for the vehicle: three rotating motions (roll, yaw, pitch) and three linear motions. The three forces are also used to determine dynamic performance, assess guideway structural design, predict ride quality, and guide the design of tastenings.

Force computation is a three-dimensional problem; sometimes, however, it can be reduced to a one- or two-dimensional problem. For electromagnetic problems, the forces can be calculated as follows from the electromagnetic field equations:

$$
\begin{aligned}
& \nabla \times \mathrm{H}=\mathrm{J}=\mathrm{J}_{\mathrm{c}}+\sigma \mathrm{V} \times \mathrm{B} \\
& \nabla \cdot \mathrm{B}=0
\end{aligned}
$$

where $\mathrm{H}$ and $\mathrm{B}$ are the magnetic field intensity and flux density, $\mathrm{J}_{\mathrm{c}}$ is the applied current density, $\sigma$ is the conductivity, and $\mathrm{V}$ is the velocity of the conductor with respect to the fields.

Knowing the distribution of magnetic field, one can compute forces on the basis of the following equation:

$$
F=\int J \times B d v
$$

where the integration is over the whole secondary conductor sheet.

Several methods are commonly used for the computation of magnetic forces for given coil geometries in maglev systems, including the finite element method, the boundary element method, Fourier transformation and harmonic analysis, and the dynamic circuit method.

\subsubsection{Shielding Problem}

In the EDS system, to achieve a large magnetic lift-to-weight ratio for practical maglev vehicles, superconducting magnets operating at high magnetomotive force are needed (i.e., with large currents). Not only can these large currents be sustained indefinitely without being connected to a power source (persistent-current mode of operation), but they can also be confined to very 
small conductor cross sections, resulting in a very high current density (because the conductors have no resistance). The high-density currents, in turn, produce very high levels of magnetic flux density near the conductors. The level of magnetic flux density, however, must be confined to the vicinity of the magnets because of the following considerations (Hayes 1987):

1. In the long term, even a low-intensity DC magnetic field may produce adverse health effects in passengers and crew members (although such effects are unknown).

2. The magnetic field may affect the way in which electronic devices function, either in the system control and communication equipment or in personal devices (such as pacemakers, watches, calculators, and tape recorders) and magnetic-information storage devices (such as credit cards, magnetic tapes, and computer discs).

3. The high density of the magnetic field may affect the normal operation of conventional iron-cored electric machines, such as pump drives for refrigeration systems.

Therefore, shielding may be necessary in order to reduce magnetic fields to acceptable levels (which have yet to be determined). Passive magnetic shielding that is made of ferromagnetic laminated sheets is usually suggested. However, the weight of this shielding can be a significant portion of the total weight of the vehicle. Thus, the design trade-offs between the location of magnetic winding (which can affect the performance of the vehicle) and the distribution of passive shielding thickness is an important research topic with respect to maglev systems.

\subsubsection{Edge-Effect Problem}

Electric machines or magnets generally have edges that are transverse to the direction of motion and that cause distortion of the magnetic field in the region of interest (i.e., in the air gap). These field distortions adversely influence the performance of the machine. This phenomenon is defined as edge effect. In a linear machine, the air gap between the primary and the secondary is usually large so that the edge effect may significantly change the performance of the entire system. In cointrast, there is no significant influence of edge effect on rotary machines because the air gap is usually small. Edge effects also change the lift, guidance, and drag forces of magnets moving over an aluminum sheet. To study the influence of edge effects on the lift, drag, and guidance of a magnet moving over a conducting sheet, a group of scientists at Argonne National Laboratory ( $A N L$ ) has conducted a number of experiments. Useful results have been obtained, but more theoretical analysis should be performed to verify those results. To study the edge effects of a linear machine or magnet at rest, two-dimensional electromagnetic field equations can be used. Inwever, to analyze the edge effects of a moving linear machine or magnet, a three-dimensional model is required. 


\subsubsection{End-Effect Problem}

The essential property that distinguishes the linear machine from the rotary machine is the open linear air gap, which has both an entry and an exit. The open-ended quality of the air gap gives rise to the unique characteristics of the linear machine. In contrast to the performance of synchronous machines, the performance of an induction machine is much more affected by end effects. In an induction machine, the high-speed movement of the reaction plate tends to prevent the penetration of the main flux produced by the stator. To study the influence of the end effect, one can generate one-, two-, or three-dimensional mathematical models, depending upon the required accuracy of the results. After the model is developed, either analytical or numerical methods can be used to solve the equations. For one- and two-dimensional models, the analytical solution may be obtainable. However, for a three-dimensional modt, the numerical method must be used. A three-dimensional model can be used to study both edge and end effects.

\subsubsection{Existing Software Packages}

To survey existing computer codes applicable to maglev problems, a questionnaire (see Appendix A) was sent to 124 investigators, requesting information on the nature, availability, and extent of validation of computer codes. Of these investigators, 27 responded to the questionnaire. Tables 1 and 2 (Arkadan 1991) summarize the computational capabilities of several commercial software packages.

A software package usually consists of three parts: preprocessing, analysis, and postprocessing. Eac'n part should be evaluated separately. The following information should be provided to the user:

1. For preprocessing:

- The way in which the geometry or the coordinates of the model are entered into the computer-aided design (CAD) drafter.

- The way in which the model geometry is stored.

- The way in which material property curves are stored.

- The way in which the finite element mesh is formed: four-node quadrilateral or three-node triangular element.

- The way in which boundary conditions are specified.

2. For analysis:

- The kinds of problem formulations that are available. 


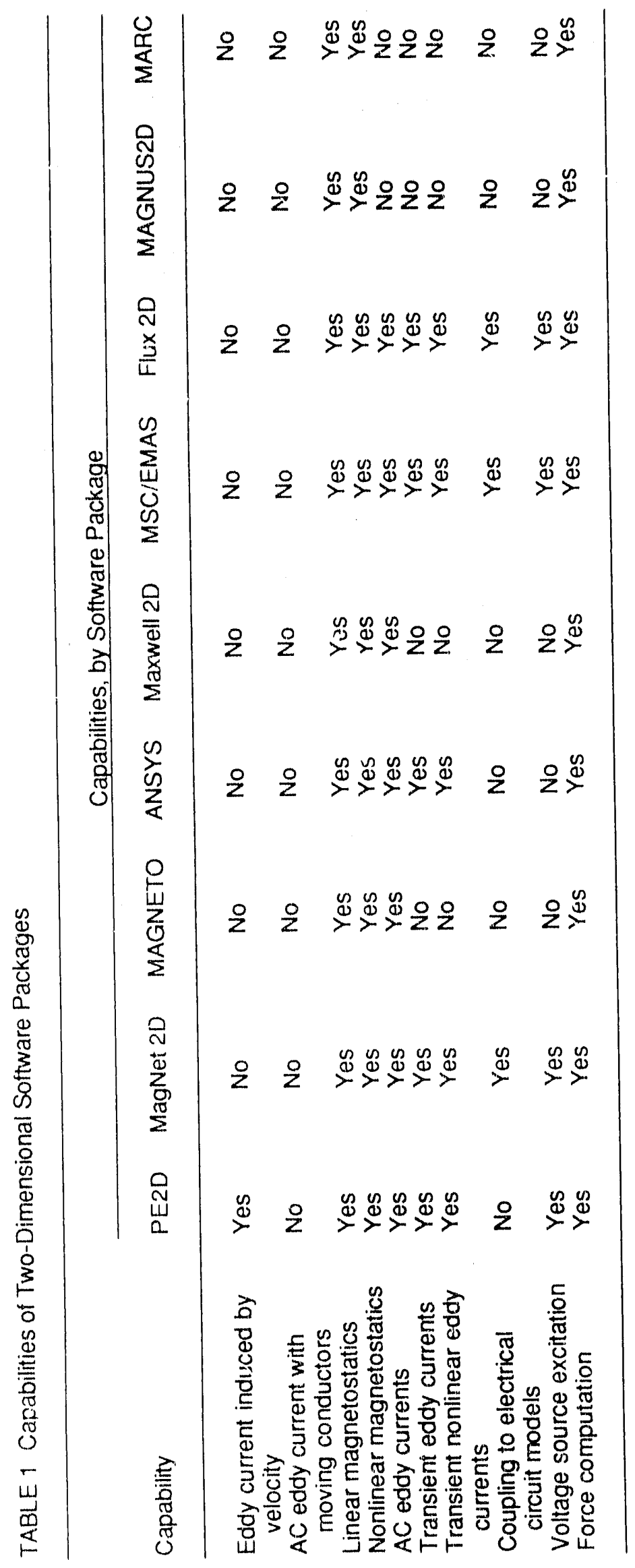




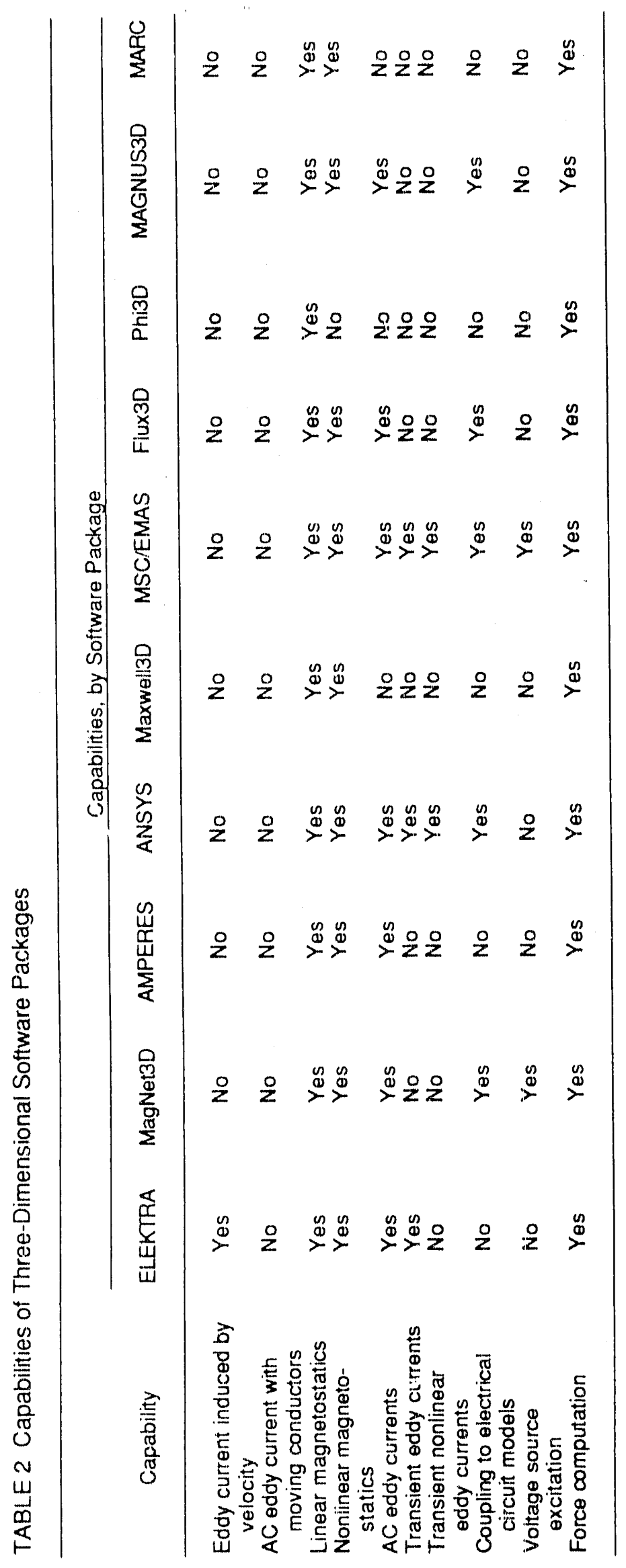


- The options that are available for first- and higher-order polynomial approximations.

- The kinds of material properties that are accounted for (such as B-H curves).

3. For postprocessing:

- The kinds of results that are available.

- The ease with which one can calculate important parameters (such as magnetic field distribution, energy, force, torque, inductance, resistance, etc.).

- The ability of other software (such as WordPerfect) to read the results.

The above criteria are for the general evaluation of commercial software. In this report, only analysis is emphasized. In particular, because most maglev problems involve relative motion between two parts (or colls), the Maxwell's equations should incorporate the appropriate velocitydependant term(s) as follows:

$$
\begin{aligned}
& \nabla \times \frac{1}{\mu} \nabla \times \mathrm{A}=\mathrm{J}=\mathrm{J}_{\mathrm{c}}+\sigma \mathrm{V} \times(\nabla \times \mathrm{A}) \\
& \nabla \times \frac{1}{\mu} \nabla \times \dot{\mathrm{A}}=\mathrm{j}=-\dot{\mathrm{j}}_{\mathrm{c}}+j \omega \sigma \sigma \mathrm{A}+\sigma \mathrm{V} \times(\nabla \times \dot{\mathrm{A}})
\end{aligned}
$$

where $A$ is a vector potential, $J_{c}$ is the applied current, $\sigma$ is the conductivity, $\omega$ is the angular frequency of the input power supply, and $V$ is the velocity of the media with respect to the fields. Therefore, to determine the extent to which the analysis part of a particular computer code is applicable to a maglev problem, it is important to know if the computer code is based on a physical and mathematical modei that contains the option of conductor motion.

On the basis of the survey results, the following capsule summaries of computer codes were compiled. These codes can be used to solve electromagnetic problems in maglev research. Because they have been commercialized, all of the following codes are already validated, except for a few new options. In addition to the codes described in detail, other software is available, such as Cosmos M (from Structure of Research and Analysis Co., 12131 454-2158), MEGA (from the University of Bath, [(2225] 826826, extension 4315), NS3D/VOLINT (from Sabbagh Association, Inc., |812/ 339-8273), and EPALS/EDS-II/LSMMIS (from PSM Technologies, Inc., |412| 829-1205). 


\section{ANSYS}

Divia opie: Swanson Analysis Systems, Inc.

Johnson Road, P.O. Box 65

Houston, Penn. 1,5342-(0)65

TWX: (510) 690-8655

Fax: (412) 746-9494

Elaine Travers: $(412) 746-33() 4 \times 103$

Avall.ABILITY: Lease.

Mirinons: Finite element.

VALIDATION: Good agreement with test data.

CAPABIITY: ANSYS was first available in 1970. It can be used to solve either two- or three-dimensional electromagnetic field problems. For both two- and threedimensional problems, it can be used to solve static magnetic field problems, which may involve saturable materials, permanent magnets, and current sources. ANSYS can be used to solve problems involving time-harmonic loads (AC currents), which may involve materials of constant permeability, as well as current sources and eddy currents. ANSYS can also be used to solve transient state problems, which may involve saturable materials, conductors, permanent magnets, current sources, and eddy currents. In addition, for two-dimensional problems only, skin effects can be studied. ANSYS has a design optimization module, which is a useful feature.

ANSYS may be used to solve some maglev-related problems, including those involving shielding, edge effects without moving conductors, eddy current analysis, saturation effects in LIM, system geometries optimal design, force computation in EMS and AC induction systems, and magnetic field distribution for given coil geometries and excitations.

ANSYS does not have the capability to solve the problem of eddy current induced by constant velocity motion of one part of the model with respect to the rest of the system.

Computiks: IBM PC, Apollo, Harris, Silicon Graphics, Celerity, Hewlett-Packard, Sun, Computervision, Prime, VAX and MicroVAX II, Data General, Ridge, Alliant, Convex, IBM (VM/CMS), CDC Cyber, and FPS. 


\section{Flux 2D/3D}

Driviloplik: Magsoft Corporation

1223 Peoples Avenue

Troy, N.Y. 12180

Philippe F. Wendling: (518) 271-1352

AVAILABLLIT: Lease or retail.

Mirnons: Finite element.

VALIDATION: Good agreement with test data.

CAPABIt.TY: Flux 2D/3D was first available in 1986. It can be used to analyze two- or three-dimensional problems, which may involve magnetostatics, magnetodynamics, and transient magnetics with lincar or nonlinear material properties.

The code can be used to solve some maglev-related problems, including those involving shielding, edge effects without motion conductors, eddy current analysis, saturation effects in LIM, force computation in EMS and $\mathrm{AC}$ induction systems, and magnetic tield dist ibution for given coil geometries and excitations.

The code does not have the capability to solve the problem of eddy current induced by constant velocity motion of one part of the model with respect to the rest of the system.

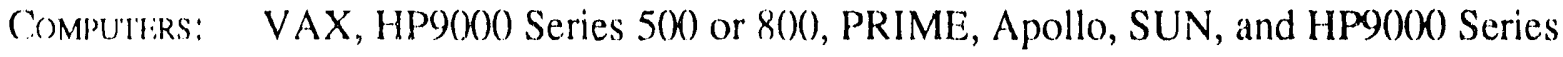
330 or 320 . 


\section{MagNet 2D/3D}

Divilooper: Infolytica Corporation

1140 de Malsonneuve St., Suite 1160)

Montreal, Canada H3A 1 M8

Fax: (514) 849-4239

Telex: 05562171 Mtl. (Attn. 1490)

Robert Rohonczy: (514) 849-8752

AvAII.ABILITY: Lease or retail.

Misuods: Finite element.

VAlidation: Good agreement with test data.

CAPABILITY: MagNet 2D/3D was first available in 1978. The two-dimensional version of MagNet 2D/3D can be used to solve two-dimensional Cartesian or axisymmetric nonlinear magnetostatic problems. MagNet 2D can handle magnetic azimuthally periodic currents and azimuthally invariant materials. An example of a problem that can be solved is edge effect in rotating machines, and the results of an edge-effect analysis of rotating machines could be applied to studies of linear machines. The code can be used to solve twodimensional Cartesian or axısymmetric nonlinear transient magnetic problems. Excitations can be defined as a function of time, such as sinusoids, square waves, and ramps.

The three-dimensional version of MagNet 2D/3D can be used to solve threedimensional eddy current problems. MagNet 2D/3D calculates the timeharmonic magnetic field in and around specified current distributions in the presence of materials that may be conductive, anisotropic, magnetic, or all three. The regions of permeability may be specified as either linear or nonlinear.

MagNet 2D/3D may solve some problems associated with maglev research, such as shielding, eddy current analysis, saturation effects in LIM, force computation in EMS and AC induction systems, and magnetic field distribution for given coil geometries and excitations. However, the code does not have the capability to solve the problem of eddy current induced by constant velocity motion of one part of the model with respect to the rest of the system.

Computers: $\quad$ IBM PC, SUN3, MicroVAX, VAXstation, A pollo 3000, Apollo 4000), HP 30(), VAX70(), SUN, VAX8(K) series, HP 800 series, Apollo 10000), Cray, and IBM mainframes. 


\section{MAGNETO/AMPERES}

Divilopir: Integrated Engineering Software, Inc.

347-435 Ellice Avenue

Winnipeg, Manitoba, Canada R3B 1 Y 6

Fax: (204) 944-8010

Jennifer A. Sherry: (204) 942-5636

AVAILABHITY: Lease or retail.

Mirilons: Boundary element.

VAliontion: Good agreement with test data.

CAP IBLITY: MAGNETO/AMPERES was first available in 1989. The boundary element method (BEM) is used to solve the integral equation formulation of a problem. A variation of the moment method, BEM merges the moment method with the finite element method and contains the best of both methods. The advantage of the BEM is its inherent ability to deal with open field problems.

With the BEM, MAGNETO/AMPERES can be used to solve two- or threedimensional electromagnetic field problems. It can be used to calculate the torque at any point (for two dimensions) or any line (for three dimensions). The code can be used to analyze nonlinearities attributable to the change in the permeability of the materials as a function of the magnetic field. The code can be used for several maglev applications, including the design and analysis of magnets (including superconducting magnets), force computation in EMS and $\mathrm{AC}$ induction systems, and magnetic ficld distribution for given coil geometries and excitations.

The code does not have the capability to solve the problem of eddy current induced by constant velocity motion of one part of the model with respect to the rest of the system.

ComputTiks: IBM PC, SUN4 (Sparcstation), HP 700) Series, and IBM RS/6000) workstations. 


\section{MAGNUS 3D}

Di:villoptik: MAGNUS Software Corporation P.O. Box 78() 1

The Woodlands, Texas 77387

Fax: (713) 292-2948

Sergio Pissanetzky: (713) 292-294

Av'All.ABILI'Y: Lease.

Mitriods: Finite element.

Validsation: No information provided; see vendor.

CAPABILITY: MAGNUS 3D was first available in 1990). It can be used to solve threedimensional electromagnetic field equations, including those involving eddy current. MAGNUS 3D uses a modular approach to generate mesh (i.e., modults of mesh of simple geometry and topology are independently generated). Hence, it is easy to simulate magners with complex geometry. Maglev-related applications include the design of superconducting magnets and the computation of force in EMS and $\mathrm{AC}$ induction systems.

The code does not have the capability to solve the problem of eddy current induced by constant velocity motion of one part of the model with respect to the rest of the systern.

Computers: $\quad$ VAX, SUN, Apollo, IBM, Cyber-205, Cray, NEC SX-2, and Macintosh Ilx. 


\section{MARC}

DivntoptiR: MARC Analysis Research Corporation

260) Sheridan Avenue Suite 3(1)9

Palo Alto, Calif. 94306

AvAILABHLITY: Lease.

Mitions: Finite element.

VAI.IDATION: No information provided; see vendor.

CAPABIIITY: MARC was first available in 1971. It can be used to solve two- or threedimensional problems, including linear static, dynamic, steady-state, and transient heat-transfer problems. MARC may solve some problems associated with maglev, including those involving magnelic field distribution for given coil geometries and excitations, shielding, force computation in EMS and $\mathrm{AC}$ induction systems, and edge effects without moving conductors.

The code does not have the capability to solve the problem of eddy current induced by constant velocity motion of one part of the model with respect to the rest of the system.

Computriks: Digital Equipment, Hewlett-Packard/Apollo, IBM, Silicon Graphics, and Sun Microsistems. 


\section{Maxwell 2D/3D}

DI:VIU.OpliR: Ansoft Corporation

Four Station Syuare Suite 660

Pittsburgh, Penn. 15219

Fax: (412) 471-9427

Karl F. Szymanskl: (412) 261-3200)

Avall.ABนL'T'Y: Lease.

Mitions: Finite element.

VAL.IDA'TION: No information provided; see vendor.

CApablitry: Maxwell 2D was first available in 1989. It can be used to solve DC magnetic problems that may involve constant, functional, anisotropic and/or nonlinear material characteristics, and excitations may be external fields, DC currents, and permanent magnets. Maxwell 2D can solve AC magnetic problems that may involve constant, functional, anisotropic and/or nonlinear material characteristics. Excitations may be external fields and AC currents; eddy current and skin effects can also be considered.

Maxwell 3D can be used only to solve DC magnetic problems. Excitations may include DC currents, permanent magnets, and external fields.

The maglev-related problems Maxwell 2D/3D may solve involve shielding, edge effects without motion conductors, eddy current analysi i, saturation effects in LIM, force computation in EMS and AC induction systems, and magnetic field distribution for given coil geometries and excitations.

The code does not have the capability to solve the problem of eddy current induced by constant velocity motion of one part of the model with respect to the rest of the system.

Computites: IBM PC, Macintosh, Apollo DN35()(4)/4()), Apollo 4()) series, HP, Sun 4, and Sun SPARCstation. 


\section{MSC/EMAS}

DiviliofliR: The MacNeal-Schwendler Corporation

9076 North Deerbrook Trail

Milwaukee, Wisc. 53223-2434

T'elex: 9102502831

Fax: (414) 357-()347

Mark M. Jenich: (414) 357-8723

AVAIL.ABILITY: LeASe.

Mritrods: Finite element.

VALIDATION: Good agreement with test data.

CAPABLITY: MSC/EMAS was first available in 1989. It can be used to solve either twoor three-dimensional problems, including those involving linear and nonlinear steady-state magnetic fields with linear isotropic or anisotropic materials or nonlinear permeable materials; sinusoidal time-varying, coupled electromagnetic fields with linear isotropic or anisotropic permeable materials; and linear or nonlinear transient electromagnetic fields with linear isotropic or anisotropic materials or nonlinear permeable materials. Several parameters, such as induced eddy current and losses, torques, forces, and Lorentz forces $(J * B)$, are available as outputs.

The maglev-related problems that MSC/EMAS can be used to address involve shielding, edge effects without motion conductors, eddy current analysis, saturation effects in LIM, force computation in EMS and $A C$ induction systems, and magnetic field distribution for given coil geometries and excitations.

The code does not have the capability to solve the problem of eddy current induced by constant velocity motion of one part of the model with respect to the rest of the system. The vendor is currently investigating the incorporation of the motion feature into ihe next productive release of the software.

Computirs: IBM PC, Apollo, MicroVAX IIm, VAX, CONVEX, Cray, and DEC. 


\section{PE2D/ELEKTRA}

Diveiloper: Vector Fields, Inc.

$17(0)$ North Farnsworth Ave.

Aurora, Ill. 60505

Fax: (708) 851-2106

Betty L. Stoub: (708) $851-1734$

AvaILABILITY: Lease or retail.

MrTHods: Finite element.

VALIDATION: Good agreement with data.

CAPABILITY: PE2D/ELEKTRA was first available in 1989. PE2D can be used to solve two-dimensional electromagnetic field problems. PE2D uses either first- or second-order triangular elements. Five analysis programs are available. The useful programs for maglev research are those involving eddy current analysis, steady-state AC currents with linear materials, transient eddy currents with multiple drives and nonlinear materials, and eddy currents induced by constant velocity motion of one part of the model with respect to the rest of the system.

ELEKTRA solves the ihree-dimensional, time-varying magnetic-field equations associated with eddy current analysis. The time variation can either be transient or time harmonic. Recently, a velocity option was added, and validation studies of this code are in progress at ANL.

PE2D/ELEKTRA may be used to solve some maglev problems, including those involving magnetic field shielding; comparisons of various suspension systems, including EMS, EDS, and AC induction systems; edge effects; eddy current analysis; saturation effects in LIM; and magnetic field distribution for given coil geometries and excitations.

The code does not have the capability to solve the problem of eddy current induced by constant velocity motion of one part of the model with respect to the rest of the system.

Computras: $\quad$ SUN, SPARCSTATION, Apollo, IBM Risc, VAXStation, InterGraph Interpro, DEC VAX, IBM 3()9(), and Cray. 


\section{Phi3D}

DEveloPtiR: Magsoft Corporation

1223 Peoples Avenue

Troy, N.Y. 12180

Philippe F. Wendling: (518) 271-1352

AvAILABILITY: Lease or retail.

Mi:Tuods: Boundary element.

VALIDATION: Good agreement with test data.

CAPABILITY: Phi3D was first available in 1990). It can be used to solve problems in linear magnetostatics and thin-skin-depth steady-state AC. For linear magnetostatics, Phi3D computes magnetic fields for materials of constant permeability caused by DC currents. For thin-skin-depth steady-state AC, it computes magnetic fields and losses for high-frequency eddy currents.

Phi3D may be useful for solving some maglev-related problems, including those involving magnetic field distributions for given coil geometries and excitations.

The code does not have the capability to solve the problem of eddy current induced by constant velocity motion of one part of the model with respect to the rest of the system.

COMPUTERS: VAX, HP9000 Series 500 or 800, PRIME, Apollo, and SUN, and HP9000 Series 330 or 320 . 


\subsection{Computational Tools for Mechanical Forces and Dynamics}

The guideway of a maglev line is expected to cost about 6()$-80 \%$ of the initial capital investment for different maglev systems. The guideway needs to meet appropriate safety requirements and achieve good ride quality; therefore, the design of the guideway is a critical area that will result in potential capital savings. One of the goals in the United States is to develop a maglev system that travels at high speed with the aforementioned qualities. One way to achieve this goal is to use computer codes, which can be used to predict the dynamic response of coupled maglev vehicle/guideway systems.

The problems and solutions of dynamic interactions of maglev vehicles and guideways first appeared in the literature 20 years ago. In addition, part of the technology (for example, secondary suspension, guideway structure, and models for vehicle/guideway interaction) for other types of vehicles (such as wheel-on-track trains) may also be applicable to maglev systems. At this time, it is important to use, whenever possible, available technologies (or at least the knowledge and computational tools acquired as a result of studying those technologies) in the development of commercial maglev systerns. In some areas, additional research will be needed in order to develop the required technology.

In this section, existing computer codes used for solving problems involving mechanical forces and dynamics that can be applied to the design of maglev vehicles and guideways are provided. The modeling of vehicles and guideways, as well as the excitation and their interactions, is summarized. Available computer codes are presented, and their capabilities, modeling techniques, extent of verification and validation, and related information are provided.

\subsubsection{Vehicle Model}

For maglev systems, different vehicle models may be used for different conditions; the models are summarized below.

1. One-Dimensional Model: Vehicles consisting of a single primary magnetic suspension and a secondary suspension on a guideway.

2. Multiple Degree-of-Freedom Model: Maglev systems with distributed suspension and rigid or elastic vehicle bodies.

3. Multiple Vehicle Model: Multiple vehicles.

Yehicle dynamics can be analyzed on the basis of various mathematical models. The objective is to provide the basic information for the evaluation of ride quality, structural integrity, and safety. 


\subsubsection{Guideway Model}

Maglev guideways can be described by different mathematical models. For a very stiff guideway with a vehicle of low mass in comparison with the mass of the guideway, the guideway can be considered a rigid body; the roughness, thermal effects, and misalignments are the excitation sources for the vehicles. With a flexible guideway, the elastic deformation of the guideway has to be considered. In gereral, the Bernoulli-Euler beam equation can be used to model the characteristics of the guideway.

The guideway may be analyzed using the finite elerient, finite difference, or modal analysis methods, depending on the parameters of the system. Maglev guideways may consist of singlespan or multiple-span beams. These guideways can be analyzed without much difficulty.

\subsubsection{Excitation and Noise}

Sources of excitation on maglev systems include the following: vehicle payload shifts, unsteady aerodynamic forces (caused by, for example, wind gusts and obstacles or initiated when the vehicle passes or enters tunnels), guideway roughness and misalignments, and perturbation of magnetic and electric fields.

Guideway roughness is an input to maglev vehicles, and it can be measured and studied statistically. The guideway profile consists of a static profile (which is attributed to static loads, construction tolerances, settlement movement of supports, thermal effects) and a dynamic profile (which is attributed to guideway deflections from traveling maglev vehicles). The guideway profile can be expressed as follows:

$$
\mathrm{G}(\mathrm{x}, \mathrm{t})=\mathrm{G}_{\mathrm{s}}(\mathrm{x})+\mathrm{G}_{\mathrm{d}}(\mathrm{x}, \mathrm{t}) \quad
$$

where the total profile $G(x, t)$ is the sum of a static profile $G_{s}(x)$, which is a function of location (and maybe of the load history), and a dynamic profile $\mathrm{G}_{d}(\mathrm{x}, \mathrm{t})$, which results from traveling vehicle loads.

Two major types of disturbances are attributed to the guideway: periodic excitation and random excitation.

\subsubsection{Periodic Excitation}

The guideway profile usually contains an ensemble of waves with varying frequencies. The deviation of the surface profile at position $x$ from a reference point along the guideway may be expressed as follows:

$$
h=\sum_{n} a_{n} \sin (\Omega x) \text { and }
$$




$$
\Omega=2 n \pi / \lambda
$$

where $a_{n}$ is the Fourier coefficient, $n$ is the wave number, and $\lambda$ is the span length.

\subsubsection{Random Excitation}

The characteristics of guideway roughness are defined in a manner easily applied to vibration studies. On the basis of a wide variety of experimental data, the power spectral density of the roughness can be expressed as follows:

$$
\mathrm{S}(\Omega)=\mathrm{A} / \Omega^{2}
$$

where $\Omega$ is the wave number in radians per meter, and $\mathrm{A}$ is the roughness amplitude in meters (its values range from $\left.0.6 \times 10^{-6} \mathrm{~m} \mathrm{to} 20 \times 10^{-6} \mathrm{~m}\right)$.

Large-impact loads may be generated during the touchdown of a maglev vehicle (because the vehicle falls as a result of the sudden loss of magnetic field) or when the vehicle runs over joints, irregularities, and misalignments of the guideway. This impact may be the most severe loading case. The longitudinal loads include magnetic and aerodynamic drag, as well as

propulsion and braking forces. The lateral loads may be due to centrifugal and guiding forces inherent in high-speed maglev, as well as wind forces.

The procedures to select the guideway parameters are as follows:

- Estimate an upper limit for guideway roughness and a range of span length.

- Estimate an upper limit for guideway deflection due to vehicle motion.

- Determine the vehicle response from an appropriate vehicle model and guideway model and, if needed, construct an ensemble of conditions based on vehicle response on a guideway or trip of specified length.

- Compare the vehicle response with the accepted ride-quality criterion.

If the guideway satisfies the arepted criteria, the selected guideway parameters are acceptable. If the guideway is not acceptable, epeat the selection process.

Noise pollution has been recognized as a national environmental problem. The noise level has to be determined inside and outside of a vehicle before the maglev system is built. Appropriate methods have to be developed to predict the noise for maglev systems. System noise will depend on the configuration of the vehicle and guideway and on the materials used in construction and fabrication. 


\subsubsection{Vehicle/Guideway Interaction}

The essential elements for vehicle/guideway interaction include vehicle dynamics, secondary suspension, primary suspension, guideway dynamics, and support dynamics. Analytical methods can be used to predict the nature of the interaction among these elements. Three different methods are used: lumped mass methods, direct numerical methods, and modal analysis methods. Different methods have different advantages; the lumped mass method is simple and easily applied for nonuniform properties, the direct numerical method is accurate but requires more computer time, and the modal analysis method is an efficient compromise between the two methods.

To account for the interactive effect, different methods are used, depending on the parameters of the system. One of the key parameters is allowable vehicle acceleration. When acceleration is less than 0.(05 g (gravity), the inertial force is much smaller than the static load, and the dynamic coupling between the vehicle and guideway is small. In this case, deflection is then used as a known displacement input to the suspension system, and the vehicle dynamic motions are analyzed using standard transfer function analysis.

When the vehicle mass is large in comparison with the guideway mass (or the vehicle accelerations are not constrained to be small), the guideway deflection may be significintly affected by the coupling of vehicles and guideways. In this case, the coupled equations of motion of the vehicle and guideway need to be solved.

\subsubsection{Simulation of Ride}

Ride quality depends on vehicle velocity, acceleration, jerk, and other factors (including noise, dust, humidity, and temperature). The fatigue time and ride index methods can be used to specify ride quality. Numerous criteria are applicable to these methods. One criterion that appears to be particularly useful is the composite model by Pepler et al. (1978). Ride index W is defined as follows:

$$
W=1.0+0.5 w_{r}+0.1|d B(B)-6.5|+17 a_{l}+17 a_{v}
$$

where $w_{r}$ is the rms (root mean square) roll rate, $a_{t}$ is the rms transverse acceleration, $a_{v}$ is the rms vertical acceleration, and $\mathrm{d} B(\mathrm{~B})$ is the noise level, in decibels, measured by using the $\mathrm{B}$-weighting system. This model incorporates the features associated with buses, trains, and airplanes, but it is not developed specifically for maglev systems.

Most simulations model the vehicle as a rigid body with several degrees of freedom. The vehicle accelerations under different conditions can be calculated by using accepted vehicle and guideway models. However, in some cases, this type of simulation may not be sufficiently accurate, because the flexibility of the vehicles may be important. In this case, the flexibility of the vehicle will have to be modeled. Although simulations under the assumption of a rigid vehicle may be flawed in ride quality analysis (because vehicle flexibility makes an important contribution to ride (quality), it maly not be feasible to perform an accurate analysis incorporating the flexibility of 
the vehicle. It is important to understand the limitations of various assumptions used in an analysis.

One of the most cost-efficient procedures in the simulation of ride quality is to use a rigid vehicle model that responds to the excitation of a flexible guideway. It is a simple matter to incorporate the effects of various system parameters once they are known. However, the major problems are associated with the lack of detailed information on the effects of the system response on ride quality, such as the interaction of different frequencies of oscillations and vehicle responses in different directions.

\subsubsection{Existing Software Packages}

Computer programs have emerged as one of the most important developments in different fields. In particular, finite element methods have becone the most useful techniques in solving practical problems on structural mechanics. Because the vehicle response, guideway vibration, and interaction of vehicles and guideways are associated with structural and fluid dynamics, many existing computer codes will be applicable to maglev. Several hundred finite element programs are available today for education, research, design, and evaluation. Several reviews have been performed to summarize the state of the art of the technology and describe the many codes, with an emphasis on structural mechanics (Pilkey and Pilkey 1975; Noor and Pilkey 1983).

Requests were sent to developers of computer programs that we believed to be applicable to maglev systems; several responses were received. In this section, only the computer codes that we believe are the most applicable to maglev vehicles and guideways, as well as those specifically developed or modified for applications to maglev systems, are summarized. Many other computer codes may be applicable to maglev systems, such as the structural response of vehicles and guideways. The details of other computer programs can be found in the two reviews by Pilkey and Pilkey (1975) and Noor and Pilkey (1983). 


\section{ACSL}

DiveilopiR: Mitchell and Gauthier Associates, Inc.

20) Baker Avenue

Concord, Mass. ()1742,-9931

William Toscano: (5()8) 369-5115

AvallabiLITY: Lease.

Mistion: Numerical solutions of initial value problems.

CAPABILI'Y: $\quad$ Modeling of the dynamic response of physical systems, including analyses of vehicle dynamics and vehicle/guideway interactions.

Vanicla Modis: $\quad$ Users' choice.

Guidiway Modil: Users' choice.

EXCT'ATION: Users' choice.

VALIDATION: The developer maintains a technical library made up of more than $34($ ) technical articles that document the application, results, and validation of the code, including ACSL results compared with empirical data.

LANGUAGi:: Fortran. 


\section{ADAM (Elliott and McConville 1990).}

Developer: $\quad$ Mechanical Dynamics, Inc. 23()1 Commonwealth Blvd.

Ann Arbor, Mich. 48105

Andrew S. Elliott: (313) 994-38(0)

Avall.ABILITY: Contact the developer.

MITHOD: $\quad$ Systems are modeled at the basic level as groups of rigid mass parts connected by joints and forces that correspond directly to physical components.

CApABils'T: Calculations of mechanical systems undergoing large displacements, including kinematic, static, quasi-static, and dynamic analyses. An extensive internal function library is available, which enables the user to model complex mechanical phenomena for user-defined differential equations and forces.

Viancle: Modia: Rigid body or elastic body.

Guidiway Modil: Elastic beams.

EXCITATION: Vehicle running over guideways and unsteady aerodynamic forces.

VALIDATION: The application of ADAM to maglev is proprictary information.

LANGIUAGE: Fortran. 


\section{AERODYNAMIC NOISE CODES}

Diveloptik: $\quad$ Sibley School of Mechanical and Aerospace Engineering

Cornell University

208 Upson Hall

Ithaca, N.Y. 14853

A.R. George: (607) 25.5-6254

Avalianitity: Contact the developer.

Mition: $\quad$ Numerical method for three-dimensional problems.

CApлвнлту: Analysis of acoustics for maglev systems.

Vialicte: Modil: Three-dimensional model.

Gundeway Modil: Three-dimensional model.

ExcTATION: Operating conditions.

VAIIDATION: No comparative or experimental data are available; general trends and parametric sensitivity believed to be correct.

LANGUAGi: Unknown. 


\section{ANLMAGLEV}

Divillopik: Argonne National Laboratory $97(0)$ South Cass Avenue Argonno, IIl. 6(0430

Y. Cai: (708) 252-3949

H.'T. Coffey: (70)8) $2.52-56.3()$

Avall.ABulity: Contact the developer.

Meriob: $\quad$ Time integration for nonlinear transient analysis with magnetic forces, acrodynamic forces, for example.

CApABntry: Prediction of dynamics of a vehicle along a curved guideway.

Vianctin: Moblat: Rigid body with six degrees of freedom.

Gumblway Monlis: Rigid guideways containing curves, hills, surface irregularities, and bank angles.

Excrition: Force, displacement, and guideway roughness.

VALIDATION: $\quad$ No information provided; see developer.

LANGUAGit: $\quad$ MS-DOS on a PC and Unix on Sun Station. 


\section{APL,DYN (Dailey, Caywood, and O'Connor 1973)}

Dinilopili $\quad$ Applied Physics Laboralory

The Johns Hopkins University

Silver Spring, Md.

George Dailey, William C. Caywood, and James S, O'Connor

AvsulibilitY: Contact the developer.

Mistuon: $\quad$ The model is based on the finlte element method, in which a complex system is made up of a number of discrete components: elements or bullding blocks, which consist of springs, dampers, masses, beams, or guideway spans; forces that are externally applied; and constraints that define the relationships between the dependent and independent degrees of freedoms.

Capabilit'Y: Calculation of the dymanic response of velicles traveling over surface or clevated guideways with prescribed irregularities. APLDYN is a general purpose computer program that is upplicable to a brond class of transportation systems; it may eliminate numerous specialized programs. The program contulns a large selection of elements or building blocks, with some restrictions. Modifications are needed for curved guideways.

Viallict: Momlit: Rigid masses connecled by springs and dampers or flexible structure.

Gunowar Monki: Flexible straight beams.

Excratron: Periodic or aperiodic forsing functions, including guideway roughness.

VAl.IDATION: No information is provided.

L.Anguncil: $\quad$ PL/I language in IBM 36()/9) 1 computer. 


\section{DYNFLEX}

Dievilomik: Department of Mechanical Engineering

The University of British Columbia

2324 Muin Mall

Vancouver, B.C.

Canada VGT IW5

D.B. Cherchas

Avall.ablitir: Contuct the developer.

Mirtion: $\quad$ Numerical methods.

Carabialtr: Analysis of dynamic response of flexible vehicles on flexible guideways with random roughness.

Vuncu Momin: T'wo-dimensional flexible vehicles.

Gumizay Modn: Flexible guideway with random roughness.

Excrintion: Guideway roughness,

VALIDA'IION: No information provided; see developer.

LANGUACH: , Fortran. 


\section{DYNSIM}

DUVHLOPIR: $\quad$ Railway Engineering Associates, Inc.

World Trade Center

401 E. Pratt St., Suite 1355

Baltimore, Md. 21202

George List: (301) 539-5575

Fiax: (301) 576-()141

Avallabilir'Y: Retail.

MITHOD: $\quad$ The model is based on the numerical integration of conventional Newtonian force-balancing relationships in all six directions.

CAPABLITY: Calculations of vehicle dynamics and vehicle/guideway interactions.

Viancie Mobli: Three-dimensional elastic bodies.

Gum:way MoDil: Beums.

EXcTrATIONS: Various operating conditions.

VALIDATION: No information provided; see developers.

Compuriess: IBM-compatible 8(0386-based PCs. 


\section{FEAP (Vu-Quoc and Olsson 1989, 1991)}

Dizviloplir: Department of Aerospace Engineering, Mechanics, and Engineering Science University of Florida

31 Aerospace Building

Gainesville, Fla. 32611

Loc Vu-Quoc: (904) 392-0961

Avallability: Shareware.

MıThod: $\quad$ Solution of ufferential equation using finite elements and finite differences.

CAPABnLITY: Analysis of the dynamic vehicle/guideway interaction of Maglev systems.

Venicle Model: Two-dimensional vehicles.

Guideway Modil: Beams.

ExcTAATION: Vehicle under operating conditions.

VAI.IDATION: No information provided; see developer.

Computres: Unix Workstations. 


\section{MAGDYN (Cherchas 1979)}

Di:VRlopir: $\quad$ Department of Mechanical Engineering

University of British Columbia

2324 Main Mall

Vancouver, B.C.

Canada V6T1W5

D.B. Cherchas

Avali,ABILITY: Contact the developer.

METHOD: $\quad$ The model includes effects of elastic deformation of vehicles and guideway, vehicle suspension, multiple guideway spans, and acrodynamic loading.

CAPABLITY: Simulation of vehicle and guideway dynamic: response for EDS.

Vancle: Monil: Rigid and elastic bodies with a combination of rigid and flexible body motion and four suspension pods and two propulsion pods.

Guideway Model: Bernoulli-Euler beams with bending in two directions and twisting.

Excrintion: $\quad$ Aerodynamic forces and moments, gravitational forces, and propulsion forces.

VAIIDATION: $\quad$ The code was not validated.

COMPUTYRS: $\quad$ IBM370/165. 


\section{MEDYNA}

Ditiloplir: $\quad$ MAN Technologie AG

Theodor-Huess-Platz 8

D-10(0) Berlin 19

W. Kik: 30 3019647

Fax: 303019744

AvAll.ABILITY: Lease/retail.

Mi:THoD: $\quad$ Natural frequencies and frequency response for linear models, numerical integration in time domain for nonlinear models, and random vibration analysis for stochastic models.

CAPABHITY: $\quad$ Analyses of the dynamics and vibration of mechanical systems, such as ground transportation vehicles and machinery. It can be used to predict the vehicle behavior, including stability, performance, and ride quality.

Viancle Molial: Rigid bodies with up to six degrees of freedom and elastic bodies in modal coordinates or chains of beams.

Guidizay Modbl: Rigid guideway with perturbations.

Excratron: Deterministic time or space functions and random excitations.

VALIDATION: $\quad$ The verification was completed by comparing the results of different programs with experimental data for railway and other types of vehicles in field tests. No special verifications have been done for maglev vehicles. Continuing development of the program is being made; it has been combined with another model, SZMPACK, to predict both linear and nonlinear response.

LAngungi: $\quad$ Fortran 77, UNIX, DOS-extended mode, VMS, BS20), NOS. 


\section{MOTION (Coffey et al. 1972, 1973, 1974)}

DEveloper: $\quad$ Argonne National Laboratory

9700 South Cass Avenue

Argonne, Ill. 60439

Howard T. Coffey: (708) 252-5630

AvaILABILITY: Contact the developer.

MıTHoD: $\quad$ Time integration for nonlinear transient analysis with magnetic levitation and guidance forces applied.

CAPABILITY: Prediction of the dynamic response for a vehicle undergoing large displacements.

VHallicli: Modil: Rigid body with six degrees of freedom.

Gumbeway MODE: Rigid and straight guideways with surface irregularities.

EXcristion: $\quad$ Force, displacement, and track perturbation.

VALIDATION: $\quad$ No information provided; see developers.

LANGUAGi: $\quad$ MS-DOS on PC. 


\section{NAGAI AND IGUCHI'S MODEL (Nagai and Iguchi 1980)}

Divialopir: $\quad$ Tokyo Universily of Agriculture and Technology

Koganei, Japan

Masao Nagai

University of Tokyo

Tokyo, Japan

Masakazu Iguchi

Avalnablitiy: Contact the developer.

Mi:THob: Modal analysis and numerical methods, including the Runge-Kutta method, are used to predict dynamic response.

CApAli ITY: $\quad$ Prediction of vibration characteristics of a long train of EMS vehicles running over flexible guideways.

Viancla: Mobra: $\quad$ Multiple vehicles are considered; each vehicle is modeled as a fourdegree-of-freedom system with heave and pitch motions of the vehicle body and heave motions of two trucks. The coupling between the vehicles and guideways is through distributed suspension forces.

Gundway Mobia: Single-span Bernoulli-Euler beams simply supported at both ends.

Excrintron: $\quad$ Vehicles over guideways for uniform and nonuniform intervals of trucks.

VAL.IDATION: No information is available; see developers.

COMPUTIRS: $\quad$ HITAC $87(0) / 88(0)$. 


\section{NUCARS (Blader 1989)}

Diveloper: $\quad$ Association of American Railroads

J.A. Elkins: (719) 584-()582

P.E. Klauser: (719) 584-(0575

AvaILABILITY: Lease.

Meriod: Time integration for nonlinear transient analysis, such as response to track irregularities, and equilibrium analysis for steady-state solution, such as curving analysis.

Capabintry: Prediction of stability, ride quality, vertical dynamics, and steady-state and dynamic curving response of rail vehicles.

Vinicla Modia: Vehicles may be modeled as rigid bodies and elastic bodies. Bodies may be linked by translational or rotational constraints. Coupling elements include nonlinear spring, damper, and friction elements.

Guidiwny Modil: Two track models are used: (1) point spring and damper model with nonlinear characteristics in vertical direction and linear stiffness and damping in lateral direction and (2) beam on Kelvin foundation model with mass and linear stiffness and damping.

Excristron: $\quad$ Force, displacement, and long wavelength track geometry inputs.

VALIDATION: $\quad$ No information provided; see developers.

LANGUAGE: $\quad$ MS-DOS on PC, Unix on Apollo or IBM RISC workstations, and VMS on VAX mainframes. 


\section{Conclusions and Recommendations}

Commercial software packages can be used to solve some maglev-related problems, including those that involve magnetic field shielding, edge effects without moving conductors, eddy current analysis, saturation effects in LIM, system optimal design, force computation in EMS and $\mathrm{AC}$ induction systems, and magnetic ficld distribution for given coil geometries and excitations. Computer programs can also be used to screen new system concepts, compare alternative designs, resolve specific dynamic problems, and perform design trade-off studies of system components. However, additional development of computer programs is needed, as outlined below.

1. For electromagnetic problems, no programs are available that can deal with AC steady-state machines associated with moving conductors. Only one company (Vector Fields, Inc.) has provided the velocity option that can be used to solve moving conductor problems* under steady-state conditions. However, to avoid significant errors, there is a limitation to this velocity option, in that the mesh size should be of the order of

$$
\frac{1}{\sigma \mu \mathrm{V}}
$$

where $\sigma$ is the conductivity, $\mu$ is the permeatility, and $V$ is the velocily. Therefore, we cannot obtain good results when the speed of the vehicle is high, unless the $n_{1}$. sh size is very small. In addition, when a system involves relative motions with space and time dependence, the finite element method requires extensive computation time in order to obtain the force-speed or force-time characteristics. Therefore, in order to simulate high-speed maglev systems, there are two suggestions:

(a) Dynamic circuit theory may be applied to maglev research (for details, see Appendix B; also see He, Rote, and Coffey 1991). It can overcome some of the limitations of the finite element method and can be used to perform three-dimensional electromagnetic analysis of maglev systems. With dynamic circuit theory, it is easy to obtain the force-speed or force-time characteristics. It is particularly suitable for the simulation of the loopshaped coil guideway, the figure-eight-shaped null-flux coil guideway, and the EDS non-sine-wave propulsion system. However, this method generally computes the forces directly. The ficld and eddy current distributions are generally not produced as intermediate results that are available as output.

\footnotetext{
*Under a special agrement with Vector Fields, Inc, members of ANL, staff are currently cvaluating this code for maglev applications involving moving conductors.
} 
(b) Because the finite element method has an inherent disadvantage for simulating high-speed motion of the conductors, the boundary element method may serve as an alternative. In the boundary element method, the mesh size is not critical, and it may avoid large errors due to the high speed of the conductors. Unfortunately, existing commercial software that uses the boundary element method does not contain the speed option. Hence, the results of this survey indicate that further efforts in computational tool development will be required before it wil! be possible to solve a variety of maglev problems involving magnetic force and moving conductors.

2. For mechanical problems, the following suggestions are made:

(a) All ride-quality criteria have their limitations, and their applicability to highspeed maglev systems remains to be determined. Ride quality for maglev systems will be an important subject for further study. Once an appropriate ride-quality criterion is developed, it can be readily incorporated into the computer corles for vehicle dynamics. For example, Ec. 9 can be used to calculate the ride index along the guideway according to the composite model by Pepler et al. (1978).

(b) The specifications required for the development of computer codes that can be used to simulate dynamic vehicle/guideway interactions are not well understooct. Once the specifications are known, appropriate codes can be developed to perform detailed analyses.

(c) The critical system parameters for EDS and EMS relative to guideway costs should be identified and studied by using scoping calculations, existing computer codes, or future programs.

(d) Very few experimental data have been gathered for a well-instrumented vehicle-guideway system, and additional detailed data on guideways, vehicles, suspension fores, and motions would be valuable. These data would be useful for validating the computer programs and assessing the performance of maglev systems.

In summary, the application of existing computer codes is useful for the development of U.S. maglev systems. However, existing programs appear incomplete because they do not contain all of the necessary capabilities for the design and evaluation of various types of maglev systems. Furthermore, the well-documented experimental data sets needed to validate existing or new codes for use in a commercial maglev system are unavailable. The development of computer codes that can be used to predict the dynamic interactions of vehicles and guideways is important for the development of U.S. maglev technology. 


\section{References}

Arkadan, A.A., 1991, Survey from Finite Element Software for Electromagnetic Applications, unpublished information, handout from a short course on finite element analysis held at Maryuette University on May 20-23.

Blader, F.B., et al., 1989, Development and Validation of a General Railroad Vehicle Dynamics: Simulation (NUCARS), Proc. of the 1989 Institute of Electrical and Electronics Engineers/American Society of Mechanical Engineers Joint Railroad Conf., April 25-27, 1989, Philadelphia, Penn., pp. 39-46.

Cherchas, D.B., 1979, A Dynamics Simulation for a High Speed Magnetically Levitated Ciuided Ground Vehicle, J. Dynamic Systems, Measurement, and Control, 101:22.3-229.

Coffey, H.T., F. Chilton, and L.O. Hoppie, 1971, Magnetic Levitation for Tomorrow's Transportation, in Advances in Cryogenic Technology, 4, R.W. Vance, ed., Xyzyx Information Corp., Los Angeles, pp. 275-298.

Coffey, H.'T., et al., 1974, An Evaluation of the Dynamics of a Magnetically Levitated Vehicle, Stanford Research Institute Report FRA-ORD and D-74-41 (NTIS No. PB236671/4GA).

Coffey, H.T., F. Chilton, and L.O. Hoppie, 1972, The Feasibility of Magnetically Levitating High Speed Ground Vehicles, Stanford Research Institute Report FRA-1001 (NTIS No. PB-2105()5).

Coffey, H.T., F. Chilton, and T.W. Barbee, 1969, Suspension and Guidance of Vehicles by Superconducting Magnets (abstract), J. Applied Physics, 40:2161, presented at Applied Superconductivity Conf. and Exhibition, Gatlinburg, Tenn., Nov.

Coffey, H.T., J.D. Colton, and K.D. Mahrer, 1973, Study of Magnetically Levitated Vellicle, Stanford Research Institute Report FRA-RT-73-24 (NTIS No. PB221696), Stanford University, Stanford, Calif.

Dailey, G., W.C. Caywood, and J.S. O'Connor, 1973, A General Purpose Computer Program for the Dynamic Simulation of Vehicle.Guideway Interactions, American Institute of Aeronautics and Astronautics J., $1 /(3): 278-282$.

E.R. Laithwaite, 1987, A History of Linear Electric Motors, MacMillan Education Ltd., London.

Eilliott, A.S., and J.B. McConville, 1990, Analyzing Rotor Dynamics with a General-Purpose Code, Mechanical Engineering, pp. 21-25, Dec.

Fujie, J., 1989, Current Status of EDS System in Japan, Proc. 11 th International Conference on Magnetically Levitated Systems and Drives, Yokohana, Japan, published by Institute of Electrical Engineering, pp. 81-83, July 7-11. 
Hayes, W.F., 1987, Magnetic Field Shielding for Electrodynamic: Maglev Vehicles, International Conf, on Maglev and Linear Drives, Las Vegas, Nev., pp. 53-66, May 19-21.

He, J.H., D.M. Rote, and H.T. Coffey, 1991, Computation of Maynetic Suspension of Maglev System.s Using Dynamic Circuit Theory, International Symp. on Magnetic Suspension Technology, National Aeronautics and Space Administration Langley Research Center, Hampton, Va., 23665-522.5, USA, Aug. 19-23.

JNR, 1983, Maglev - Transportation for Tomorrow, Japanese National Railway (JNR) brochure (in English).

Johnson, L.R., et al., 1989, Maglev Vehicles and Superconductor Technology: Integration of High-Speed Ground Transportation into the Air Travel System, Argonne National Laboratory Report ANL/CNSV-67, April.

Menden, W.W., J. Mayer, and D. Rogg, 1989, State of Development and Future Prospects of the Maglev-Systems Transrapid, M-Bahn and Starlin, Proc. 11 th International Conf. on Magnetically Levitated Systems and Drives, Yokohama, Japan, published by Institute of Electrical Engineering, Japan, pp. 11-18, July 7-11.

Miller, L., and W. Rouss, 1989, Performance Analysis of the Transrapid 07, Proc, 11th International Conf, on Magnetically Levitated Systems and Drives, Yokohama, Japan, published by Institute of Electrical Engineering, Japan, pp. 85-92, July 7-11.

Nagai, M., and M. Iguchi, 1980, Dynamic Characteristics of a Long Train of EML Vehicles over Elevated Flexible Guideways, Bulletin of the Japan Society of Mechanical Engineers, 23(184):166.3-1669.

Noor, A.K., and W. Pilkey, 1983, State-of-the-Art Survey on Finite Element Methodology, published by the American Society of Mechanical Engineers, New York, N.Y.

Pepler, R.D., et al., 1978, Development of Techniques and Data for Evaluating Ride Quality, Vol. 1: Summary, Dunlap and Associates, Inc., Department of Transportation Report DO'T.-TSCRSPD-77-1, I.

Pilkey, W., and B. Pilkey, 1975, Shock and Vibration Computer Programs: Reviews and Summaries, The Shock and Vibration Information Center, Naval Research Laboratory, Washington, D.C.

Powell, J.R., and G.R. Danby, 1969, Magnetically Suspended Trains: The Applications of Superconductor to High Speed Transport, Cryogenics and Industrial Gases, p. 19.

Vu-Quoc, L., and M. Olsson, 1989, Formulation of a Basic Building-Block Model for Interaction of High-Speed Vehicles on Flexible Structures, J. of Applied Mechanics, 56(2):451-458. 
Vu-Quoc, L., and M. Olsson, 1991, New Predlctor/Corrector Algorithms with Improved linergy Balance for a Recent Formulation of Dynamic Vehicle/Structure Interaction, Intermutional J, of Numerical Methoxds in Engineering, 32:223-253. 


\section{Appendix A: \\ Questionnalre and Letter Used in Survey of Computer Codes}

Denr Collengue:

Muy9, 1991

One of the tasks ANL. has been asked to perform in support of the Natlonal Muglev Initiative (NMI) is to report on the status of eomputational tools.

The types of computer cordes that are of interest are those that can be used to compune:

1. Magnetic field distributions given coll geometries, excitations, and relative motion.

2. Magnetic field shielding.

3. Levitation, guddance, drug, and propulsion forces, eddy current and magnetic field distributions for various coil geometries, excitutions, and relutive motions.

4. Dymamic: response of magnetically levitated vehickes (linked and unlinked) to various force transients (guideway irregularitics, wind loads, paylond shlfts, etc.), including the effects of flexible guldeway spans, grades, curves, tumnels, etc. given the number and location of magnets, vartous inputs (such as magnetic force stiffesess) and damping function: for primary and secondary suspension systems. Abllity to handle active suspension is also of interest.

5. Estimates of ride quality connected with item 4 above and comparisons with various standards.

6. Aerodynamic drag forces and noise emissions from vehicle/guideway configurations.

7. Propulsion and power system design and operating parameters, including block length, coil geometry, voltage, current, power, power factor, and efficiency as a function of operating conditions, stuch as vehicle size, vehicle speed, and acceleration.

Please complete the attached guestionnaire for each computer code that you would like to have included in the survey report, which will be distributed to participants in the National Maglev Iniriative. Please keep your answers brief?

'Thank you for your assistance.

Sincerely,

Donald M. Role

7() $8 / 972-3786$

Danvial Meyer

$7(08 / 972-6489$ 
Please apply the following guestions to your eodo which best sults the needs mentioned on the previous page. Circle all answers (marked with • ) which apply to your code and to the cluestion all hand, filling in unswers whore necessary. Skip any unapplicable questions.

1. Prolluct nume'?

2. Formulation of code: What does it accomplish?

- Dimension of spaco simulated - 'Two - Three

- Solution of differential eyuations using finte differences

- Numerical integration using quadrature techniques

- Cinte elements

- Other

Approximate execution time for typical problem?

On machine?

3. What kinds of problems can be solved? (Please use space at bottom of page to explain)

- Electromagnetic field (ff yes, does it include speed term, i.e. motion eddy current.)

- Vehicle dymamics

- Vehicle-Guideway interictions

- Structural analysis

- Other

4. Coxle input/output procedures: Can foreign data be accessed by the code? -Yes - No If yes, what formats are supported?

5. User Interface: - Menu driven - Mouse support - Glll - Graphical output

6. lionalat of code: - Functions - lall software package - Library - Other Type of cosde: - lixecutable - Source corde

lor what type of machine?

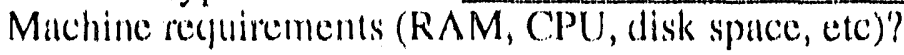

7. Distribution method: - Lease - PD - Shareware - Free - Retail - Price?

8. Documentation: - Manual - Reports - Code commentary - Flow charts - Technical Papers - Other

9. Support availible: -Toll-free number - Onsite help - Training - Other

10. Status of verification: Deres the code do what it's intended to do'? - Yes - No lixplain:

11. Status of validation: How well does the model correspond to the real world?

Do moxlel calculations accuralely reflect results obtained in laboratory or field?

-Yes $\quad$ No

Vixplinin: 


\section{Appendix B:}

\section{Introduction to Dynamic Circuit Theory}

The dynamic circuit theory is also called general machinery theory or the mesh-matrix method. It can be used to perform thre -dimensional electrodynamic analysis of maglev systems. With the dynamic circuit theory, an electrodynamic system can be described by a set of differential equations with space- and time-dependent circuit parameters. If plate or sheer conductors are contalned in the system, the conductors will be divided into many zones, each of which carries different current. Once the lumped-circuit parameters for every conducting zone are determined, a set of differential equations in the form of matrix is formed. After equations for the current distributions are solved, the force acting between the system components can be known. Thus, the performance of the system can be determined. Because the dynamic circuit theory treats a set of equations in the time domain, it is suitable for the computer simulation of an electrodynamic system, especially for a maglev system.

A maglev system can be represented by the dynamic circuit model in which the system cnergy, force, and power can be expressed in terms of circuit parameters. Consider a maglev system in which $m$ vehicle coils interact with $n$ guideway coils to produce propulsion, levitation, and guidance forces. On the basis of Kirchhoff's voltage law, the system voltage equations can be written in matrix form:

$$
\left.|e|=\mid R \| i]+v_{x} \mid G_{x} \| i\right]+v_{y}\left|G_{y}\left\|i\left|+v_{z}\right| G_{z}\right\| i\right|+\frac{d}{d t}\{|L||i|\}
$$

where [i] and [e] are column $(m+n)$ matrices made up of the individual currents and voltages associated with the vehicle and guideway coils, respectively; $|\mathrm{R}|$ is a diagonal $(\mathrm{m}+\mathrm{n}$ elements) resistance matrix; $|L|$ is a $(m+n)$ by $(m+n)$ matrix whose elcrnents represent either self-inductances or mutual inductances between the vehicle coils and guideway coils; $v_{x}, v_{y}$, and $v_{z}$ are the velocities of the vehicle in the $x, y$, and $z$ directions, respectively; and $\left|G_{x}\right|=d[L] / d x$, $\left|G_{y}\right|=d|L| / d y$, and $\left|G_{z}\right|=d|L| / d z$. Therefore, the three force components $F_{x}, F_{y}$, and $F_{z}$ acting on the vehicle can be obtained from the following equations:

$$
\begin{aligned}
& F_{x}=\frac{1}{2}|i|^{\mathrm{T}}\left|G_{x}\right|[i] \\
& F_{y}=\frac{1}{2}|i|^{T}\left|G_{y}\right||i| \\
& F_{z}=\frac{1}{2}|i|^{T}\left|G_{h}\right|[i]
\end{aligned}
$$

The equations look very simple. The key point is how to obtain the expression of the matrix of inductances associated with relative positions between vehicle coils and guideway coils. 

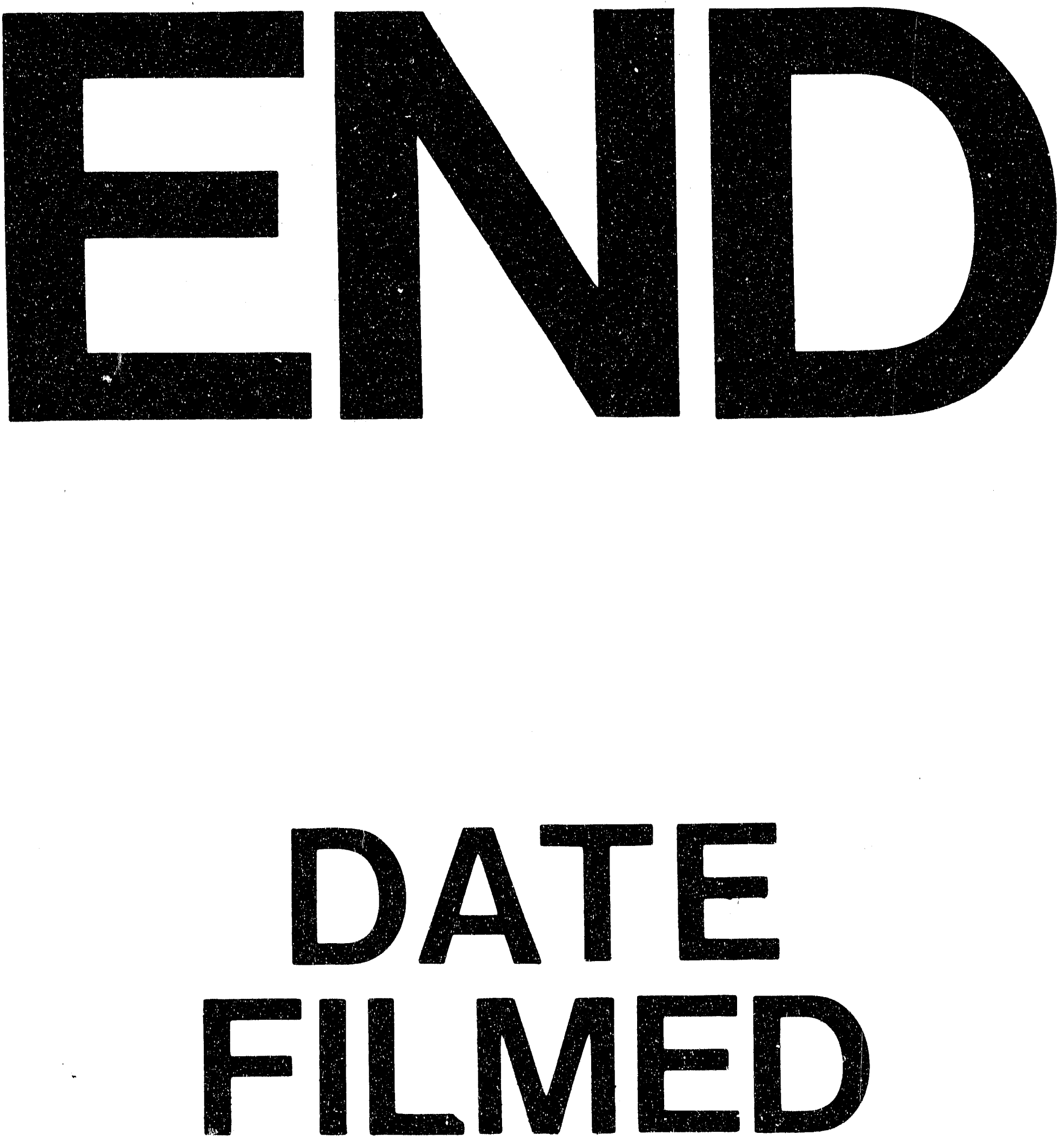

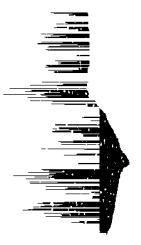

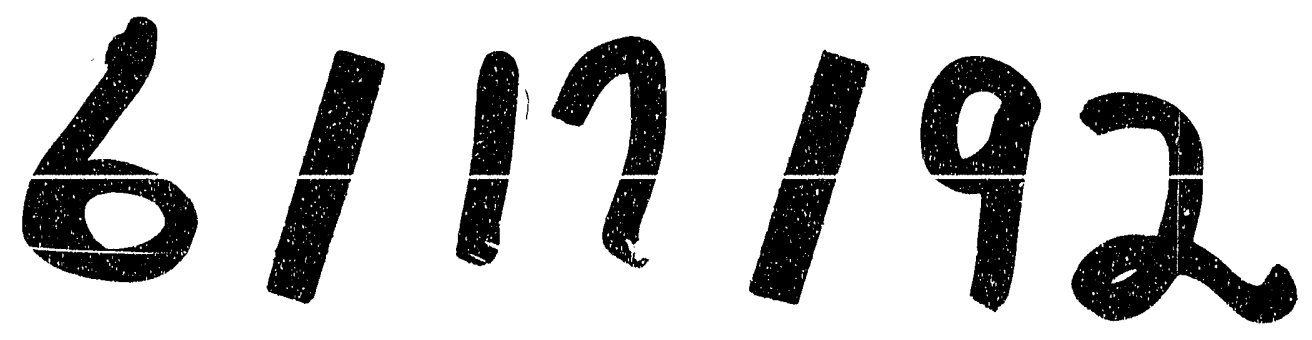




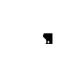

